\title{
Review and evaluation of: European Manual of Medicine
}

\section{Otorhinolaryngology, Head and Neck Surgery}

\author{
Asgaut Warland
}

Published online: 10 August 2010

(C) The Author(s) 2010. This article is published with open access at Springerlink.com

The aim of this paper back book of more than 700 pages is to offer residents as well as specialized clinicians the latest and most up-to-date information on diagnosis and treatment in ORL-HNS in Europe.

This book is easy to read. Most of the ENT-organs are presented in a systematic way starting with a presentation of clinical anatomy and physiology. Then follows a description of clinical examinations and technical diagnostic procedures as well as imaging. In some chapters, however, this systematic approach is not followed. The chapters presenting the thyroid gland and the chapter of head and neck tumors start directly with presentation of different diseases without presenting clinical anatomy and physiology and examinations.

Each disease is described systematically including aetiology, symptoms, diagnostic procedures, treatment and complications.

Most of the chapters are supplied with an abundance of beautiful color figures of pathological findings. Again, however, a few chapters have none or very few figures, e.g. in the chapters of benign and malignant tumors of the larynx. Many of the chapters are supplied with very nice flowcharts presenting diagnostic procedures.

For diseases where there are no European unanimous procedures for diagnostics and treatment, the procedure performed in some of the major countries is described.

In my opinion, the authors have largely succeeded with their aims with this book.

It could be "the bible" for residents.

It could also serve as a reference book for medical students who are specially interested in ENT.

Open Access This article is distributed under the terms of the Creative Commons Attribution Noncommercial License which permits any noncommercial use, distribution, and reproduction in any medium, provided the original author(s) and source are credited.

A. Warland $(\bowtie)$

Section of Audiology,

Department of Otolaryngology/Head andNeck Surgery,

Haukeland University Hospital, 5021 Bergen, Norway

e-mail: asgaut.warland@helse-bergen.no 